\title{
Water flow simulation and emergent treatment procedure of water supply channel without control gate
}

\author{
Ke Kong ${ }^{1, a}$, Kun Wang ${ }^{1, b}$ and Zhenghe $\mathrm{Xu}^{1, \mathrm{c}}$ \\ ${ }^{1}$ University of Jinan, Jinan, Shandong Province, China \\ aemail:koker@sohu.com, bemail:1015157780@qq.coml, cemail:xu4045@126.com
}

\begin{abstract}
Keywords: water supply channel; simulation; Mike11; control gate; emergent treatment
Abstract. It is difficult for reservoirs to guarantee their main water supply aims when the water demands are tremendous and the control gats in its water supply channel are inavailable. In this papper three monitor points are set in the start, the middle and the end of the channel of the Jinxiuchuan reservoir. The collected monitoring data are input into Mike11 to simulate the procedure of water flow procedure in this channel during the irrigation period when the rural water demand and municipal water demand are conflict. The relationship of water amount achieved by the municipal users and the water levels along the channel are analyzed; the threshold values of water supply risk are obtained, so that the emergent treatment program is made, which can provide technology support for reservoir's water supply decision.
\end{abstract}

\section{Introduction}

Water supply is the main task for the reservoir. In common, the reservoir has one more tasks, so it is necessary to find efficient way to coordinate the different water usage ways such as power generation, irrigation, municipal use, even environment protection [1,2]. The water resources is inadequate in Shandong province in China, so the conflict of water demand and supply is intensive and the multi-object reservoir can hardly guarantee its main water supply aim especially there is no control engineering such as sluice alone the water supply channel. In this condition simulation method based monitoring data is a facilitate way to help reservoir to make water supply scheme. The Jinxiuchuan reservoir located in the south mountain area of Jinan city in Shandong province is a multi-object reservoir. It has three tasks: power generation, irrigation water supply and municipal water supply. The water supply efficiency and reliability are important for the water safety of Jinan $[3,4]$.During the irrigation period in every year the irrigation amount is very large which effect the warrant ratio of municipal supply which is the most important aim of the reservoir. The actual difficult is that there is no sluice to control the water flow which is induced by the villages alone the water supply channel. In this study three monitor points are set to get real-time information of water flow and the Mike11 is used to simulate the water flow procedure in channel during water supply, so that the risk of water inadequate for municipal can be forecasted and the emergent program can be made to ensure the reservoir can take correct measures for water discharge.

\section{The Jinxiuchuan Reservoir and Main Water Supply Channel}

The Jinxiuchuan reservoir controls $166 \mathrm{~km}^{2}$ area, locates in the upper-stream of the Yufu River which flows through three rural cities : Xiying, Jinxiuchuan and Zhonggong, and goes into the Wohu reservoir. The main water supply channel of the Jinxiuchuan reservoir is made of concrete with rectangle sections, includes 13 tunnels and 10 launders, and locates in the south of the Lichen district in Jinan city, with $31.5 \mathrm{~km}$ long. It begins from the discharge port under the dam and ends in the Fenshuiling water plant which disposes water and send to the south part of the Jinan city. Along the channel there are 22 villages. 
The main water supply task for the reservoirs is municipal water, i.e. the water sent to the end of the channel, the Fenshuiling water plant. The guarantee ration of the municipal water is $95 \%$, the water amount required is 20 million $\mathrm{m}^{3}$. The irrigation water is the second task with a $75 \%$ guarantee ratio and 3.5 million $\mathrm{m}^{3}$ water drained by the villages. Because there is no control sluice during the channel, the reservoir can't limit the villages drain water. In the irrigation period the conflict between rural and urban is intense, so the main task may be disturbed. In this condition, three monitor sites are set, one in channel head, one in channel end i.e. Fenshuiling water plant and on in Quanlu, the middle of the channel. Based on the monitor data using the simulation method to obtain the water flow procedure, the reservoir can forecast the incoming water inadequacy in Fenshuiling plant through the real time data in the three monitor sites and can adjust its discharge scheme emergently. The simulation tool chosen hers is Mike11 which used widely in many fields of water resources [5,6]. It is efficient enough for the water flow analysis.

\section{Model Set and Simulation}

Model Set. The basic module in Mike11 involved in this simulation study is $\mathrm{HD}$ (hydraulic dynamic) module, which simulate water flow in channel based Saint-Venant equations that includes continual quality equation and momentum equation, showed as Eq.1. In Mike11, the format to solve this differential equation group is Abbott format.

$$
\left\{\begin{array}{l}
B \mathrm{~s} \frac{\partial \mathrm{h}}{\partial \mathrm{t}}+\frac{\partial Q}{\partial \mathrm{x}}=q \\
\frac{\partial Q}{\partial \mathrm{t}}+\frac{\partial}{\partial x}\left(\frac{\alpha Q^{2}}{A}\right)+g A \frac{\partial \mathrm{h}}{\partial x}+\frac{g Q}{C^{2}} \frac{|Q|}{A R}=0
\end{array}\right.
$$

where $x$ denotes the coordinate of space; $t$ denotes the coordinate of time; $Q$ denotes quantity of flow; $h$ denotes water level; $A$ denotes section area; $R$ denotes hydraulic radius; $B s$ denotes river width; $\mathrm{q}$ denotes flow income from branch; $C$ denotes Chezy coefficient; $g$ denotes acceleration of gravity; $\alpha$ denotes coefficient of speed spread.

Mike11 HD need some configuration files to carry out simulation, the main files includes river net file, sections file, boundary files and parameters files. The study object is the main water supply channel of the Jinxiuchuan reservoir, so the river net is simply the lineal channel from beginning, the reservoirs discharge port, to the end, the Fenshuiling water plant which is the receiver of municipal water. The sections file includes the locations of the 45 different sections along the channel, the shapes in different sections, the hydraulic radius of river segments that divided by sections, and so on. Segments in this model are set not more than $5000 \mathrm{~m}$ to balance the accuracy and efficiency of the computation. The boundary file sets the terminal points where there are income or outcome water flows. The reservoir discharge port is the channel head terminal and the Fenshuiling water plant is the channel end terminal. Other parameters needed in the HD model such as river bed roughness, initial water level, level of water bed are all included in the parameter files, some of them are set artificially and some of them needed to be calibrated.

The 22 villages along the channel drain water through pumps. Another module in Mike11, SO, which deals with control structures are needed to describe such hydraulic engineering's drainage behaviors. The locations of the drainage pump work which finally summed to 13 are configured and the flux ranges through pumps are set as shown in Fig 1.

Model Calibration and Validation. The main parameter needed calibration is roughness of river bed that relates to the shape of river bed, the curve of river course, plant cover, water level and artificial hydraulic works. In order to avoid the disturbing of branch discharge, this paper selected the monitor data in the January of the year of 2016 when there is non-irrigation and the water plant is the 
only water receiver. The simulation time step is 1 hour. The result is 0.029 . The data from 2016-2-4 to 2016-2-5 are used to validate the results. The residual errors (RE) between series of monitor data the simulation data are calculated and the Nash efficiency coefficient (DC) is used also to measure the calibration results, which is shown is Table 1. The final RE and DC are all small enough to guarantee that the calibration is validated.

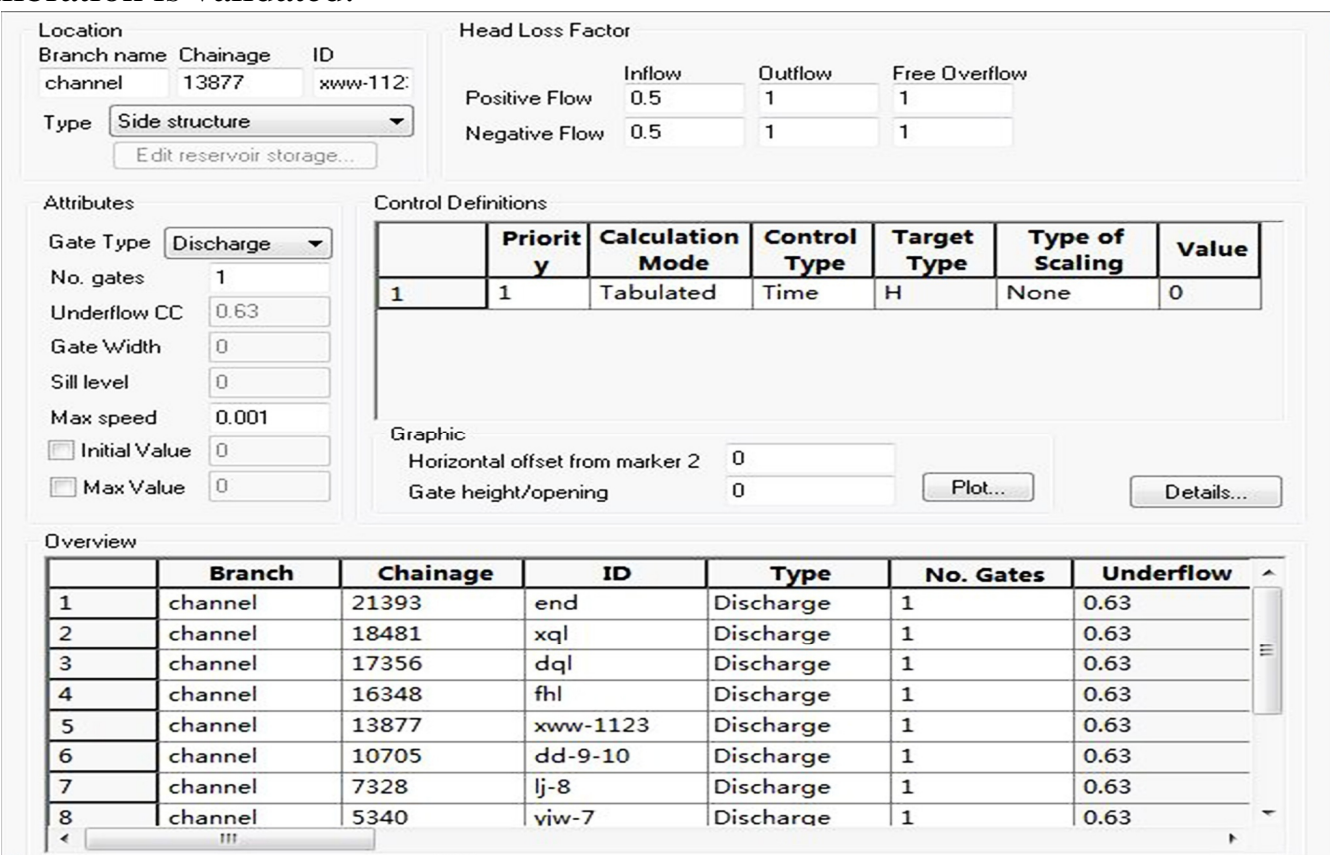

Fig.1. Pumps setting

Table 1 Model parameter validation

\begin{tabular}{ccccc}
\hline Time & $\begin{array}{c}\text { Monitor } \\
\text { flux }\left[\mathrm{m}^{3} / \mathrm{s}\right]\end{array}$ & $\begin{array}{c}\text { Simulation } \\
\text { flux }\left[\mathrm{m}^{3} / \mathrm{s}\right]\end{array}$ & $\operatorname{Re}[\%]$ & DC \\
\hline 2016/2/4 0:00 & 0.275 & 0.273 & -0.73 & \\
2016/2/4 6:00 & 0.276 & 0.275 & -0.36 & \\
2016/2/4 12:00 & 0.264 & 0.269 & 1.89 & \\
2016/2/4 18:00 & 0.271 & 0.276 & 1.85 & \\
2016/2/5 0:00 & 0.273 & 0.27 & -1.10 & 0.07 \\
2016/2/5 6:00 & 0.273 & 0.27 & -1.10 & \\
2016/2/5 12:00 & 0.269 & 0.272 & 1.12 & \\
2016/2/5 18:00 & 0.269 & 0.273 & 1.49 & \\
\hline
\end{tabular}

Water Flow Simulation. In ordinary time of the year, the water supply procedure is smooth, because the rural water demand is little and steady, so that the municipal water supply is the main task of the reservoir and it is can easily be guaranteed. But from the March to May, the irrigation water demand is tremendous, the villages drain water from channel as they wish, so that the water amount arrive in the water plant in the end of the channel may be disturbed. If the inadequate water can be forecasted through some threshold values of water levels and fluxes in the places of middle point, i.e. Quanlu and the end point, i.e. water plant, the reservoir can take emergent treatment such as increases the discharge flux available to avoid the income water supply risk for municipal water demand which is its main water supply task.

In order to simulate the supply water flow during the irrigation period, at first the pumps should be set as above. The situation of March is taken as typical situation in the irrigation months. The drainage 
time is set as three day from 5am to $12 \mathrm{pm}$ in the beginning of March, the drainage amount is obtained by statistics from the district, and the discharge flux is set as the average level during past decade, $0.9-2.4 \mathrm{~m}^{3} / \mathrm{s}$. Because of the effect of time delay, the time span of simulation is extended from February 27th to March 3th in practice and the step is $1 \mathrm{~h}$. Through the simulation, we can learn that the normal water level in Quanlu is from $0.65 \mathrm{~m}$ to $0.88 \mathrm{~m}$, and the simultaneous flux in water plant is from $0.6-0.73 \mathrm{~m}^{3} / \mathrm{s}$, which are all determined by the number of working pumps. If the water flux and level can be kept steadily in such ranges, the municipal water demand can be ensured. The arrival time of water form channel head to Quanlu is about $12 \mathrm{~h}$ and to Fenshuiling is about $15 \mathrm{~h}$.

\section{Emergent Treatment Procedure}

Because the drainage in irrigation period is uncertain, so when the flux in water plant is below $0.6 \mathrm{~m}^{3} / \mathrm{s}$, it not always leads to serious inadequacy. If the data in the channel head and Quanlu are high enough, it will recover in some hours, so it is not necessary to increase reservoir's discharge flux which is kind of excessive treatment. On the other hand if the data are below the threshold values above, the reservoir must increase its discharge flux emergently to avoid the severe disturbance. The emergent treatment procedure is shown as follows:

(1) Monitor the real time data in water plant, Quanlu and channel head.

(2) If the flux in water plant is above $0.6 \mathrm{~m}^{3} / \mathrm{s}$, it is normal, if not, to step(3).

(3) If the discharge flux of channel head is above $0.9 \mathrm{~m}^{3} / \mathrm{s}$ and the water level in Quanlu is above $0.8 \mathrm{~m}$, the low flux in water plant is temporary, keep monitor; if not, to step(4).

(4) If the discharge flux of channel head is above $0.9 \mathrm{~m}^{3} / \mathrm{s}$ and the water level in Quanlu is under $0.8 \mathrm{~m}$, increase the channel head discharge flux to $1.5 \mathrm{~m}^{3} / \mathrm{s}$, if not, to $\operatorname{step}(5)$.

(5) If the water level in Quanlu is above $0.8 \mathrm{~m}$, increase the channel head discharge flux to $1.5 \mathrm{~m}^{3} / \mathrm{s}$, if not, increase it to $2.4 \mathrm{~m}^{3} / \mathrm{s}$.

\section{Conclusions}

Actual water supply can't be studied by prototype experiment, so the simulation method is important for rational decision of reservoir especially there is no control gate to limit the uncertain drainage form sub-important water users such as irrigation during the water channel. This paper uses Mike11 to simulate the water flow in water supply channel of the Jinxiuchuan reservoir water. The relationship of water level and water flux in three monitor points are obtained, and the threshold values are used to make correct emergent treatment procedure which can avoid the municipal disturbance from irrigation drainage and avoid excessive increase of water discharge from reservoir.

\section{Acknowledgements}

This paper is supported by Shandong nature science fund (ZR2012DL08) and Shandong major water resources science research and technology promotion project (SDSLKY201314, SDSLKY201308, SDSLKY201410). Jinan water environment harness technology study and promotion project (SHMS2015-3-01)

\section{References}

[1] B. Malekmohammadi, B. Zahraie and R. Kerachian: Expert Systems with Applications Vol.38(2011), p.7851.

[2] F. L. Yang and X.F. Zhang: Procedia Environmental Sciences Vol.13( 2012), p.928.

[3] S. Li and B. Ma: Shandong Water Resources (2012) No.10, p.44 (in Chinese). 
[4] Q.H. Li and B. Ma: Shandong Water Resources (2013) No.11, p.38 (in Chinese).

[5] G. G. Morianou, N. N. Kourgialas, G. P. Karatzas and N. P. Nikolaidis: Procedia Engineering Vol.162(2016), p.46.

[6] C.Doulgeris, P. Georgiou, D. Papadimos and D. Papamichail: Journal of Environmental Management Vol.94( 2012), p.132. 